\title{
Characterization of Microstructure, Strength, and Toughness of Dissimilar Weldments of Inconel 625 and Duplex Stainless Steel SAF 2205
}

\author{
R. Sridhar $\cdot$ K. Devendranath Ramkumar $\cdot$ N. Arivazhagan
}

Received: 25 January 2014/Revised: 21 February 2014/Published online: 3 August 2014

(C) The Chinese Society for Metals and Springer-Verlag Berlin Heidelberg 2014

\begin{abstract}
The dissimilar combinations of Inconel 625 and duplex stainless steel SAF 2205 obtained from manual GTA welding process employing ER2209 and ERNiCrMo-3 filler metals have been investigated. Formation of secondary phases at the HAZ of Inconel 625 and grain coarsening at the HAZ of SAF 2205 were witnessed while using these filler wires. The average hardness of ER2209 weldments was found to be greater than ERNiCrMo-3 weld. Tensile fracture was observed at the weld zones for both the fillers. Impact test trials showed brittle mode of fracture on employing ER2209 filler and mixed (ductile-brittle) mode of fracture while using ERNiCrMo-3 filler. Further optical microscopy and SEM/EDS analysis were carried out across the weldments to investigate the structure-property relationships.
\end{abstract}

KEY WORDS: Inconel 625; Duplex stainless steel; SAF 2205; Dissimilar metal welding; Microstructure; Mechanical characterization

\section{Introduction}

Nickel-based superalloys and stainless steels are widely used in high temperature environments such as steam generators, reformer, and pyrolysis tubes in oil refineries [1-3]. In addition, these dissimilar combinations are used in petrochemical factories and nuclear power plants, where a combination of the strength and resistance to corrosion is required [4-6]. van Wijngaarden and Chater [7] reported the use of these joints in the geothermal power plants where Inconel 625 operates in high temperature and Duplex 2205 in sub-zero temperature. The applications of

Available online at http://link.springer.com/journal/40195

R. Sridhar · K. D. Ramkumar $(\bowtie) \cdot N$. Arivazhagan

School of Mechanical \& Building Sciences, VIT University,

Vellore 632014, India

e-mail: deva@vit.ac.in

R. Sridhar

Saraswathy Velu College of Engineering, Vellore, India bimetallic joints on Inconel and stainless steel series had been reported also [8-10].

One of the key issues in the welding of Ni-based superalloy with stainless steels is the selection of appropriate filler metal. Naffakh et al. [8] employed gas tungsten arc welding (GTAW) for joining Inconel 657 and AISI 310 using Inconel 82, Inconel A, Inconel 617, and 310 austenitic stainless steel filler wires. It was reported that the weld microstructure was found to have fully austenitic structure for all the filler wires. Similar observations were made by Shah Hosseini et al. [9] who carried out the investigations on the mechanical properties of Inconel 617 and AISI 310 stainless steel.

Lee et al. [11] reported that the increase of $\mathrm{Nb}$ in filler metal composition led to the formation of equiaxed dendrites. The authors also reported that $\mathrm{Nb}$ addition increases the yield strength and reduces the elongation with no apparent influence in tensile strength while welding nickelbase alloy 690 to SUS 304L. Welding of super alloy with stainless steel has a number of challenges such as ductilitydip cracking (DDC), hydrogen cracking, and formation of brittle phases in the weld and weld interface which could 
cause inferior mechanical and metallurgical properties. Ductility-dip cracking susceptibility was observed to be one of the major problems during the multi-pass welding of Inconel 625 [12]. Belloni et al. [13] reported that the use of filler metal employing higher $\mathrm{Nb}$ constituent enhances the mechanical properties but however the segregation of $\mathrm{Nb}$ forms the Nb-rich phase, which is a brittle compound that has detrimental effect on weldability and weld mechanical properties such as ductility, fracture toughness, fatigue, and creep rupture.

Further it was reported that the presence of $3 \mathrm{wt} \% \mathrm{Nb}$ stabilizes the austenitic matrix in the weld zone [9]. Also the presence of iron in nickel-based superalloys lowers the niobium solubility in austenite phase and the presence of Niobium not only lowers the melting point constitutionally, but also forms low-melting carbide-austenite eutectics during solidification [8].

Dissimilar weld joints between Inconel 625 and Duplex stainless steel have particular use in high temperature applications where the combination of enhanced mechanical properties and corrosion resistance is required. As evident from the open literature, very limited studies have been reported on these combinations of joints. Continuous current gas tungsten arc welding technique is employed using two different filler metals such as ER2209 and ERNiCrMo-3 to investigate and compare the penetration, grain refinement, and segregation effects which influence the weld quality. Further, the studies reported in the article addressed the effect of filler wire on metallurgical and mechanical properties of these dissimilar weldments.

\section{Experimental}

The nominal chemical compositions of the as-received base metals and filler metals have been studied using wet spectroscopic method and are presented in Table 1 . The base metals with the dimension of $125 \mathrm{~mm} \times 50 \mathrm{~mm} \times 5 \mathrm{~mm}$ were employed in this study. Two filler metals such as ER2209 and ERNiCrMo-3 have been chosen as these filler metals are compatible with the base metals employed. The process parameters were ascertained based on the previous studies and also by iterative studies based on the bead on plate welding and are represented in Table 2.

Standard V-groove butt joints (single V-groove having a root gap of $2 \mathrm{~mm}$, size land of $1 \mathrm{~mm}$, and included angle of $70^{\circ}$ ) were employed for welding these dissimilar metals. A specially designed fixture with a copper back plate that could clamp the base metals firmly so as to avoid distortion and bending was employed. The weldments were characterized for any defects using gamma ray radiography technique. Subsequent to the results, the welded samples were cut into different coupons for further analysis.

The macro and microstructure studies were performed on the coupons termed as "composite regions" which covers all the zones [parent metals, heat affected zones (HAZs), and weld zone]. Standard metallographic procedures were adopted for examining the microstructure of the weldments. Electrolytic etching (10\% oxalic acid solution, $6 \mathrm{~V}$ DC supply of $1 \mathrm{~A} / \mathrm{cm}^{2}$ ) was employed to examine the microstructure of Inconel 625 and SAF 2205. Further, the SEM/EDS analysis was performed on the various zones of

Table 1 Chemical compositions of the base/filler metals (in wt\%)

\begin{tabular}{|c|c|c|c|c|c|c|c|c|c|}
\hline Materials & C & $\mathrm{Mn}$ & $\mathrm{Cr}$ & Mo & $\mathrm{Fe}$ & $\mathrm{Nb}$ & $\mathrm{Ni}$ & $\mathrm{N}$ & Others \\
\hline Inconel 625 & 0.022 & 0.169 & 22.80 & 9.33 & 4.24 & 2.98 & 59.65 & - & $\begin{array}{l}\text { Si } 0.104 ; \mathrm{Cu} 0.157 ; \mathrm{P} 0.004 ; \\
\text { S 0.010; Al 0.101; Co }<0.005 \text {; Ti } 0.235 \text {; Ta }<0.02\end{array}$ \\
\hline UNS 2205 & 0.028 & 1.32 & 23.16 & 3.19 & Bal. & - & 5.20 & 0.149 & Si $0.372 ;$ P $0.026 ;$ S 0.005 \\
\hline ER2209 & 0.024 & 1.6 & 22.19 & 3.1 & Bal. & - & 9.0 & 0.16 & P 0.016; S 0.005 \\
\hline ERNiCrMo-3 & 0.05 & 0.18 & 22.4 & 9.2 & 0.8 & 3.8 & Bal & - & $\begin{array}{l}\text { Ti 0.22; Cu 0.25; S 0.004; } \\
\text { P 0.024; Si 0.20 }\end{array}$ \\
\hline
\end{tabular}

Table 2 Process parameters employed in the GTA welding using different filler metals

\begin{tabular}{llllll}
\hline Filler & Welding pass & Voltage $(\mathrm{V})$ & Current (A) & $\begin{array}{l}\text { Shielding gas flow } \\
\text { rate (L/min) }\end{array}$ & $\begin{array}{l}\text { Filler wire } \\
\text { dia. }(\mathrm{mm})\end{array}$ \\
\hline ER2209 & Root pass & $10.9-11.1$ & $151-152$ & 15 & 2.4 \\
& Remaining passes & $16.1-16.4$ & $170-172$ & 15 & 2.4 \\
ERNiCrMo-3 & Root pass & $11.1-11.4$ & $151-152$ & 15 & 15 \\
& Remaining passes & $12.4-14.6$ & $152-170$ & & \\
\hline
\end{tabular}




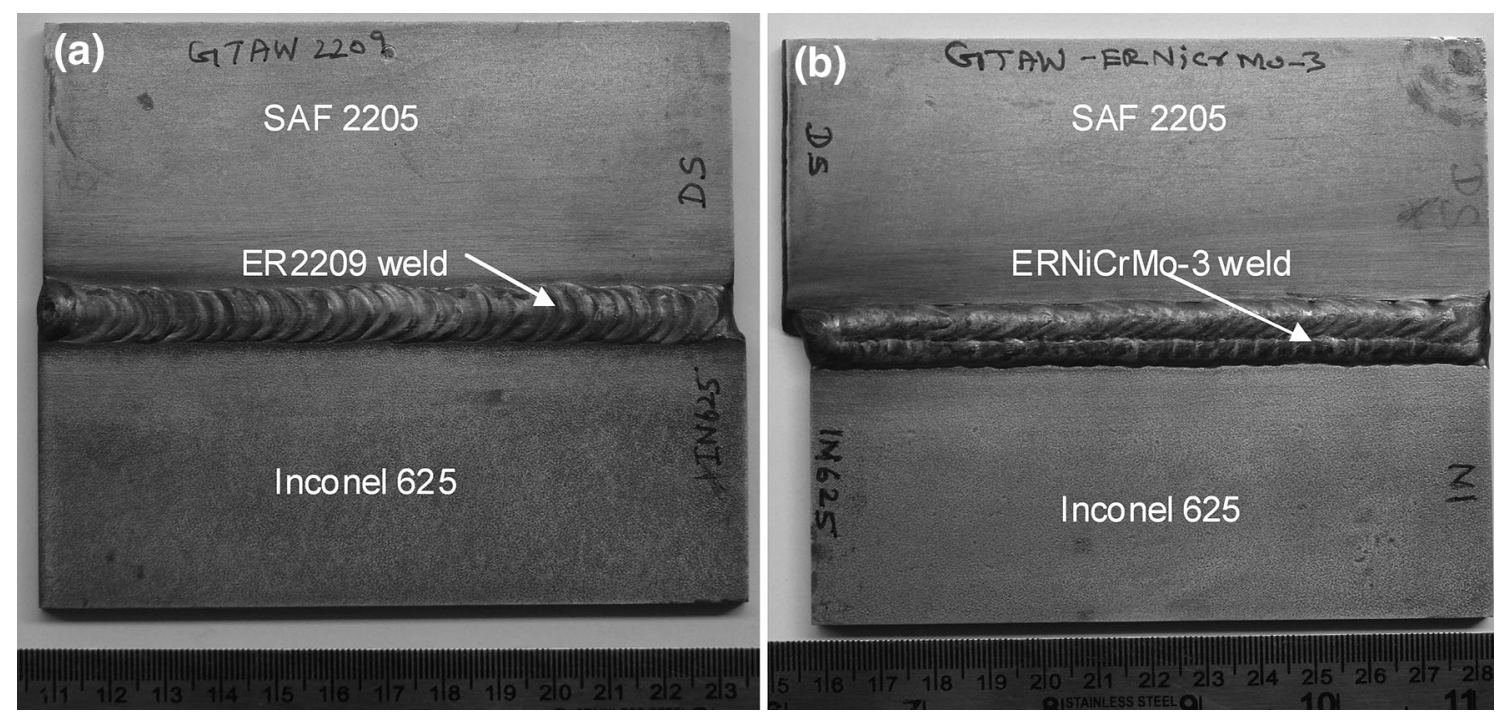

Fig. 1 Photographs of the GTA weldments employing ER2209 a, ERNiCrMo-3 b fillers

the weldments to determine the presence of various elements and also helpful to assess the structure-property correlations.

Further to estimate the mechanical properties of dissimilar joints of Inconel 625 and Duplex stainless steel, various tests were performed. Three samples were tested for tensile and impact test for determining the repeatability of the results. Tensile studies were carried out on the weldments which were fabricated as per ASTM E8/8M standards. These samples were tested at a strain rate of $2 \mathrm{~mm} / \mathrm{min}$ at room temperature. Charpy V-notch impact test samples were prepared and tested according to ASTM E23-12C standards of sub-sized specimens by simple beam method. Notches were made such that fracture occurred only within the weld fusion zones. Furthermore the fractured samples were characterized for SEM analysis to determine the mode of fracture. Hardness measurement was carried out on the composite region of the weldments across three distinct zones vis-à-vis cap, filler pass, and root of the weldments using Vicker's micro-hardness tester with a load of $4.9 \mathrm{~N}$ for a dwell time period of $10 \mathrm{~s}$ at regular intervals of $0.25 \mathrm{~mm}$. The following chapter addresses the results and discussion of the experimental work.

\section{Results and Discussion}

\subsection{Macrostructure}

The photographs of the weldments shown in Fig. 1 clearly indicated that the joining of dissimilar metals involving Inconel 625 and SAF 2205 could be possible on employing these filler metals and the welding technique. It is understood from the cross-sectional macrostructure studies that apposite
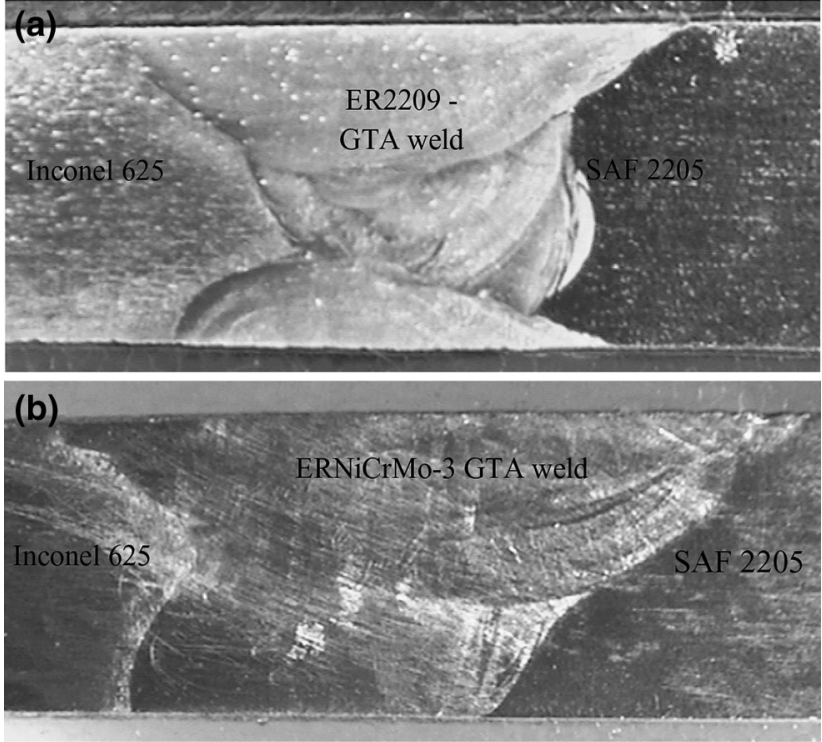

Fig. 2 Macrostructure of the dissimilar weldments of Inconel 625 and SAF 2205 Duplex stainless steel employing ER2209 a, ERNiCrMo-3 b fillers

fusion had occurred with the base metals on using GTA welding process, as shown in Fig. 2. No physical surface defects like arc strike, cracks, and undercut have been observed in any of these weldments. It is witnessed that the selection of filler wire and process parameters are appropriate for both cases. Moreover, proper weld pool morphology without any macro defects obtained in the macro graph confirmed for the proper weld fusion. Also gamma ray nondestructive testing (NDT) inspection clearly corroborated that the weldments were free from subsurface weld defects such as inclusions, porosity, and lack of fusion etc. 

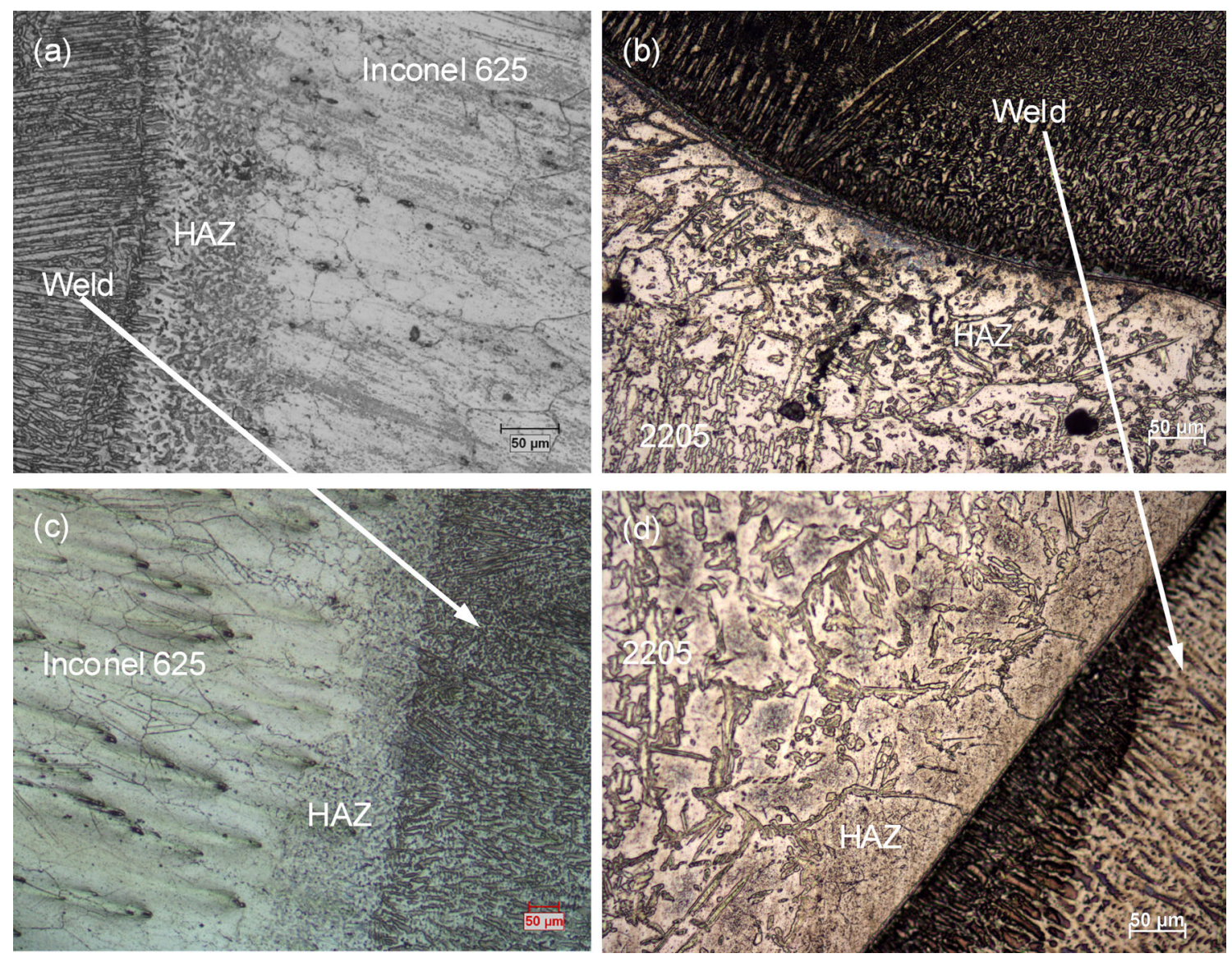

Fig. 3 Microstructure showing dissimilar Inconel 625 and SAF 2205 weldments employing ER2209 a, b; ERNiCrMo-3 c, d fillers

\subsection{Microstructure}

The interface microstructure between filler ER2209 weld metal and Inconel 625 clearly witnessed the considerable precipitation/un-mixed zone which is represented in Fig. 3a and $b$. This could be acquainted to the differences in the melting temperature of filler and base metal which causes poor dilution in the re-solidification stage. Interestingly, well defined fusion line is noticed at the interface of ER2209 and SAF 2205 due to compatibility of filler and base metal. It is also observed that more grain growth has occurred in the SAF $2205 \mathrm{HAZ}$ due to the temperature increase during various welding passes. On the other hand, grain boundary thickening with epitaxial growth could be seen in the HAZ of the Inconel 625. This may be due to formation of low melting secondary phases at these boundaries. The weld microstructure adjacent to Inconel 625 side consists of austenitic matrix with some inter- and intra-granular precipitates in the equiaxed long dendritic arms. In contrast, the cellular grain growths were observed near the SAF 2205 side on employing ER2209 filler.

The interfacial micrograph of the filler ERNiCrMo-3 weld metal and the parent metals of Inconel 625 and SAF 2205 is represented in Fig. 3c and d. Similar to the ER2209 weld, a remarkable layer of precipitation zone was noticed at the fusion zone and in Inconel 625; however, the width of the precipitation zone is meager in comparison with ER2209 welds which could be probably due to the proper dilution of the filler metal with the base metal Inconel 625 . Further, the reason could be attributed to the similarities existing in the melting temperature and chemical composition of ERNiCrMo-3 and Inconel 625.

In addition, the columnar growth occurs at the weld zone adjacent to the Inconel 625 side. On the other hand, combination of equiaxed and cellular dendrite was noticed in the weld center. Figure $3 \mathrm{~d}$ represents the interface of ERNiCrMo3 weld metal, and SAF 2205 inferred the slight thickening of fusion line which could be attributed to less compatibility of the base metal with ERNiCrMo-3 filler wire compared to ER2209 filler. The grain growth with fine precipitates along the solidification grain and sub-grain boundaries was observed in the HAZ of SAF 2205 side. However, this phenomenon is found to be absent on using ER2209 filler wire.

Formation of secondary phases or the segregation effects at the HAZ of Inconel 625 and grain coarsening at the HAZ of SAF 2205 for both the filler metals is inferred from the micrographs (Fig. 3a-d). This could be attributed 

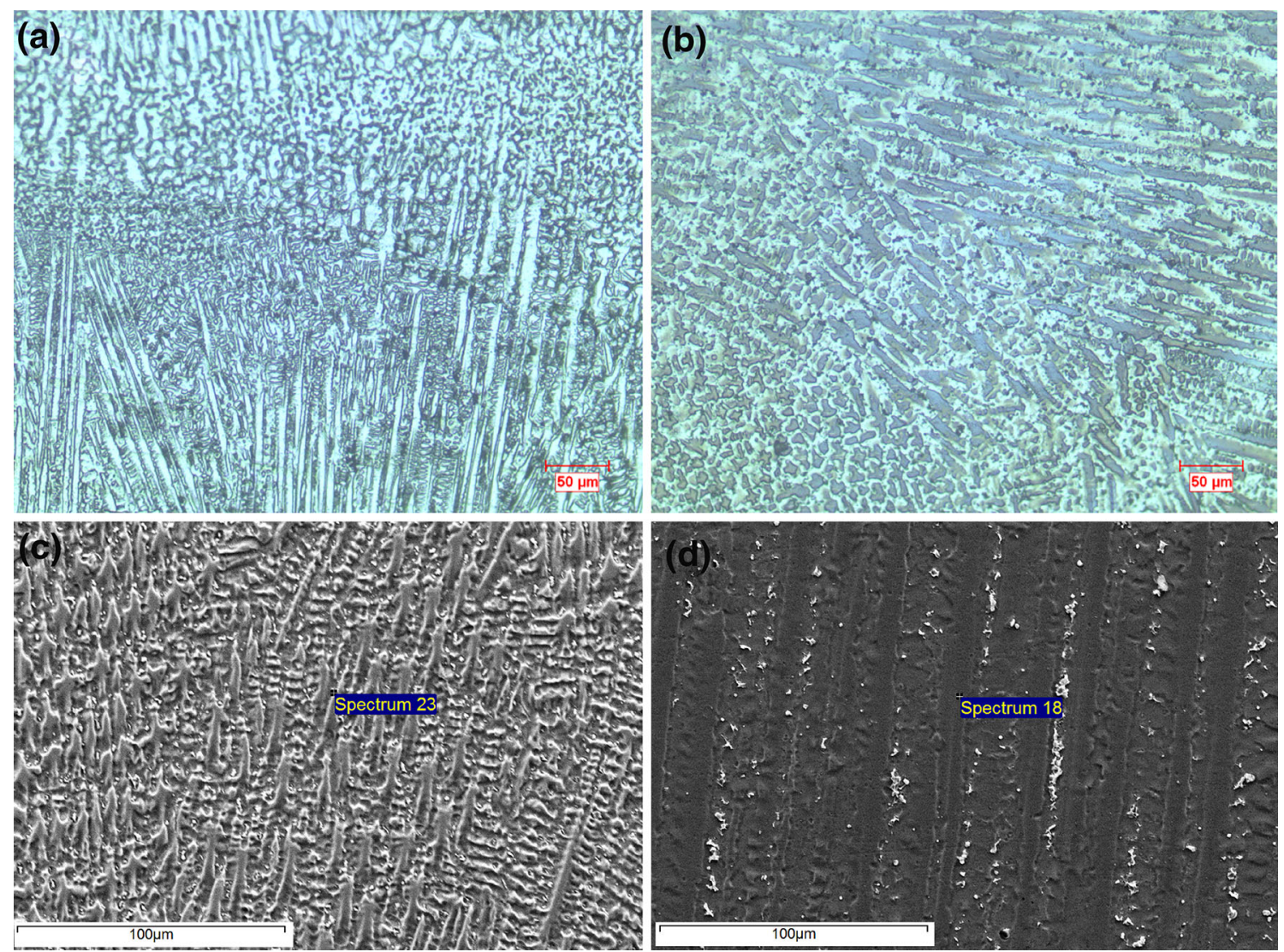

Fig. 4 Weld microstructures of the dissimilar Inconel 625 and SAF 2205 weldments employing ER2209 a, ERNiCrMo-3 b fillers; SEM photographs at the weld zone ER2209 c, ERNiCrMo-3 d fillers

to the higher heat inputs developed during GTA welding resulting in slow cooling rate. Columnar dendrites with inter-dendritic arms were observed at the weld zone employing ER2209 filler. Fine dispersed secondary phases were also witnessed in between the inter-dendritic regions across the entire zone, as shown in Fig. $4 \mathrm{a}$ and c. The dendrite network in dark clearly appears in back-scattered electrons due to the segregation of heavy elements $\mathrm{Nb}$ and Mo in the inter-dendritic spaces which appear in a lighter tone, as shown in Fig. $4 \mathrm{~b}$ and d. According to the existing literatures, the elements $\mathrm{Mo}, \mathrm{Si}$ and, more particularly, $\mathrm{Nb}$ are rejected in the inter-dendritic liquid during the solidification process, $\mathrm{Ni}$ and $\mathrm{Fe}$ being concentrated in the dendrite cores and are evident from the EDS analysis reported in the subsequent sections.

\subsection{SEM and EDS Analysis}

\subsubsection{SEM and EDAX Analysis on ER2209 Weldments}

SEM and EDAX line mapping results of GTA ER2209 weld interface of Inconel 625 are represented in Fig. 5a. SEM images witnessed the micrograph of the weldment which is discussed in the earlier Sect. 3.2. EDAX analysis results showed that there is enrichment of $\mathrm{Mo}$ and $\mathrm{Fe}$ in the weld interface adjacent to Inconel 625 . This is attributed to migration of Fe from SAF 2205 and Mo from Inconel 625 during the welding process, which is caused due to the differences in elemental concentration gradients of base and filler metal. The presence of secondary phases was observed, and these phases could be enriched with $\mathrm{Fe}-\mathrm{Ni}$ $\mathrm{Cr}$ as evident from the EDS results.

Figure $5 \mathrm{~b}$ represents the SEM and corresponding line mapping results at the interface of ER2209 weld and SAF 2205. Similar to earlier discussion, there is an enrichment of $\mathrm{Ni}, \mathrm{Mo}$ and $\mathrm{Fe}$ in the weld zone. However the segregation of Mo in the boundaries of the dendrite is highly predominated as compared to other interface. Further, the results inferred the depletion of Mo and $\mathrm{Ni}$ in the weld interface and this is evident from the migration of these elements as discussed in the earlier section. Figure $4 d$ shows the presence of austenitic matrix containing chains of secondary phases in a skeleton structure. Different orientation and colors of these phases could be ascribed to the difference in solidification rate due to atomic weight of the concentrated elements. Further the EDS results also witnessed that there is enrichment of elements like $\mathrm{Fe}, \mathrm{Cr}$, Mo and $\mathrm{C}$. 

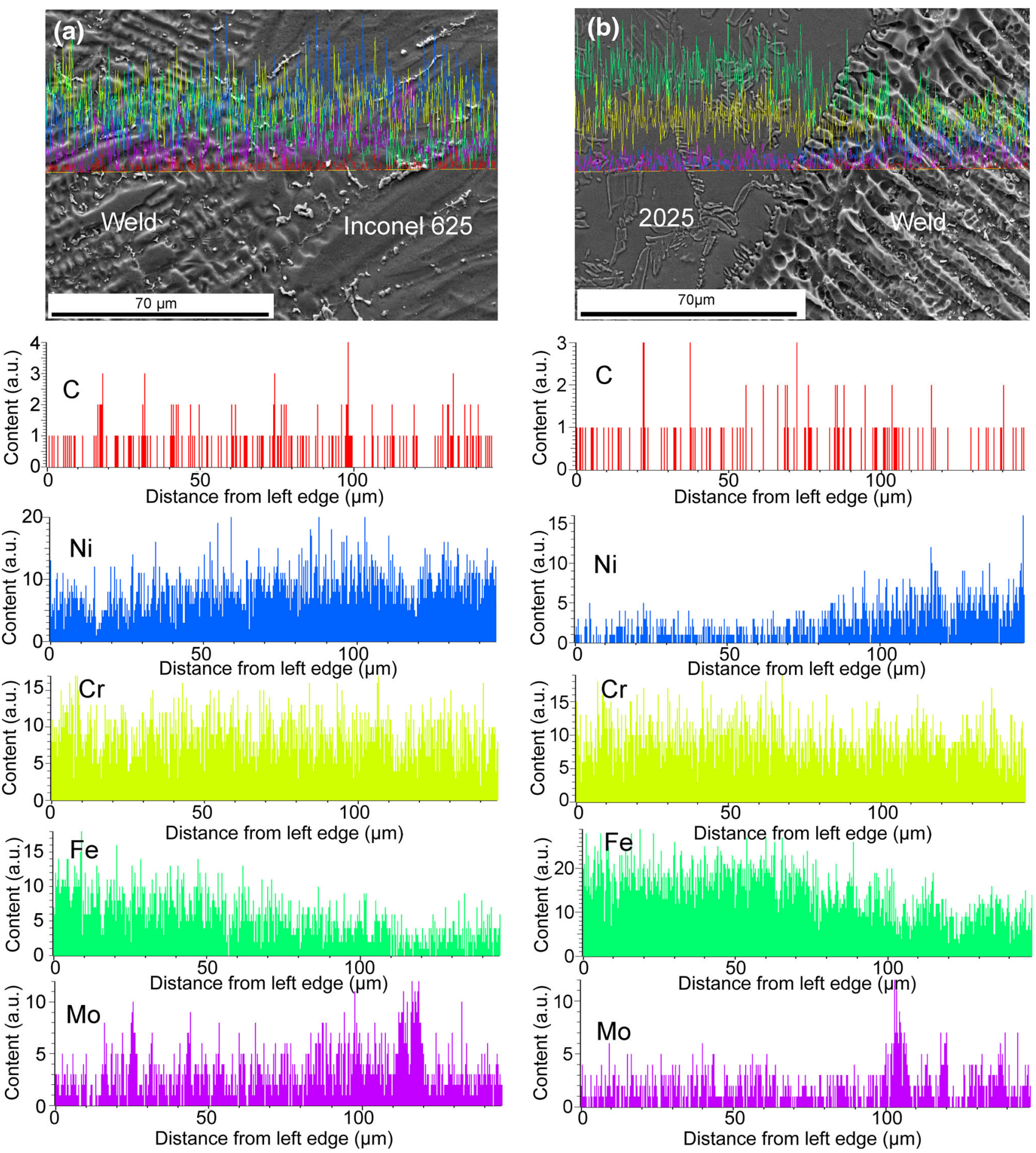

Fig. 5 Line mapping analysis on the dissimilar weldments employing ER2209 filler: a interface at Inconel 625 side; b interface at SAF 2205 side

EDS point analysis on ER2209 weld interface of both SAF 2205 and Inconel 625 is represented in Fig. 6. The presence of voids has been observed at the weld zone adjacent to the interface of SAF 2205 employing ER2209. This could be attributed to the depletion of $\mathrm{Cr}$ which evaporated during welding. It is also confirmed from the point analysis that the presence of $\mathrm{Cr}$ is $20.89 \mathrm{wt} \%$ which is lower at the voids as compared to dendritic core (Fig. 6a, b). Segregation has been observed as white precipitates at the weld fusion zone adjacent to the Inconel 625 side (Fig. 6c). As evident from the EDS results, these segregations are enriched with elements such as $\mathrm{Nb}(5.81 \mathrm{wt} \%)$, 

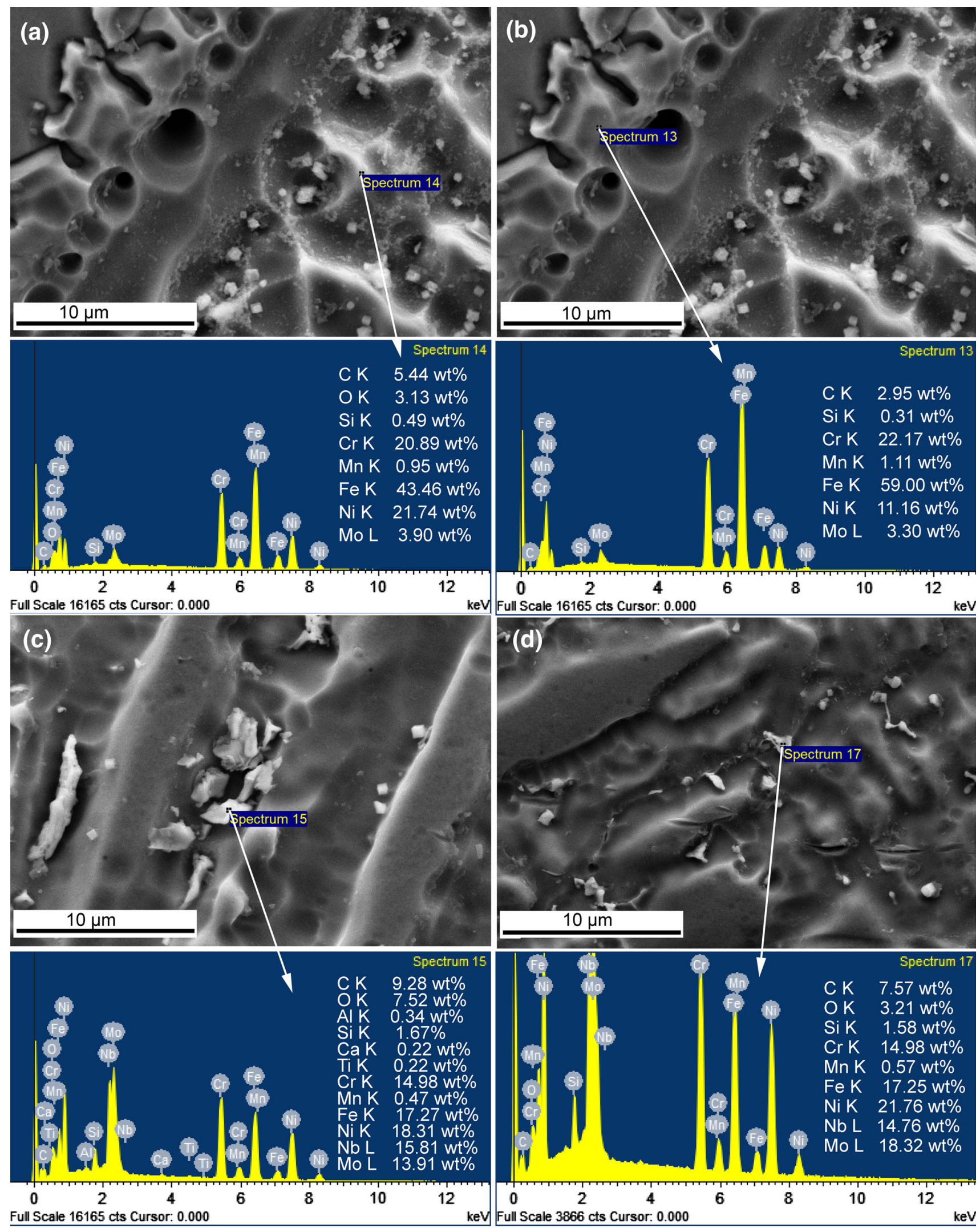

Fig. 6 SEM/EDAX point analysis on the weld zone of the dissimilar weldments of Inconel 625 and SAF 2205 employing ER2209 filler: a, b weld zone at the SAF 2205 side; c, d weld zone at the Inconel 625 side 

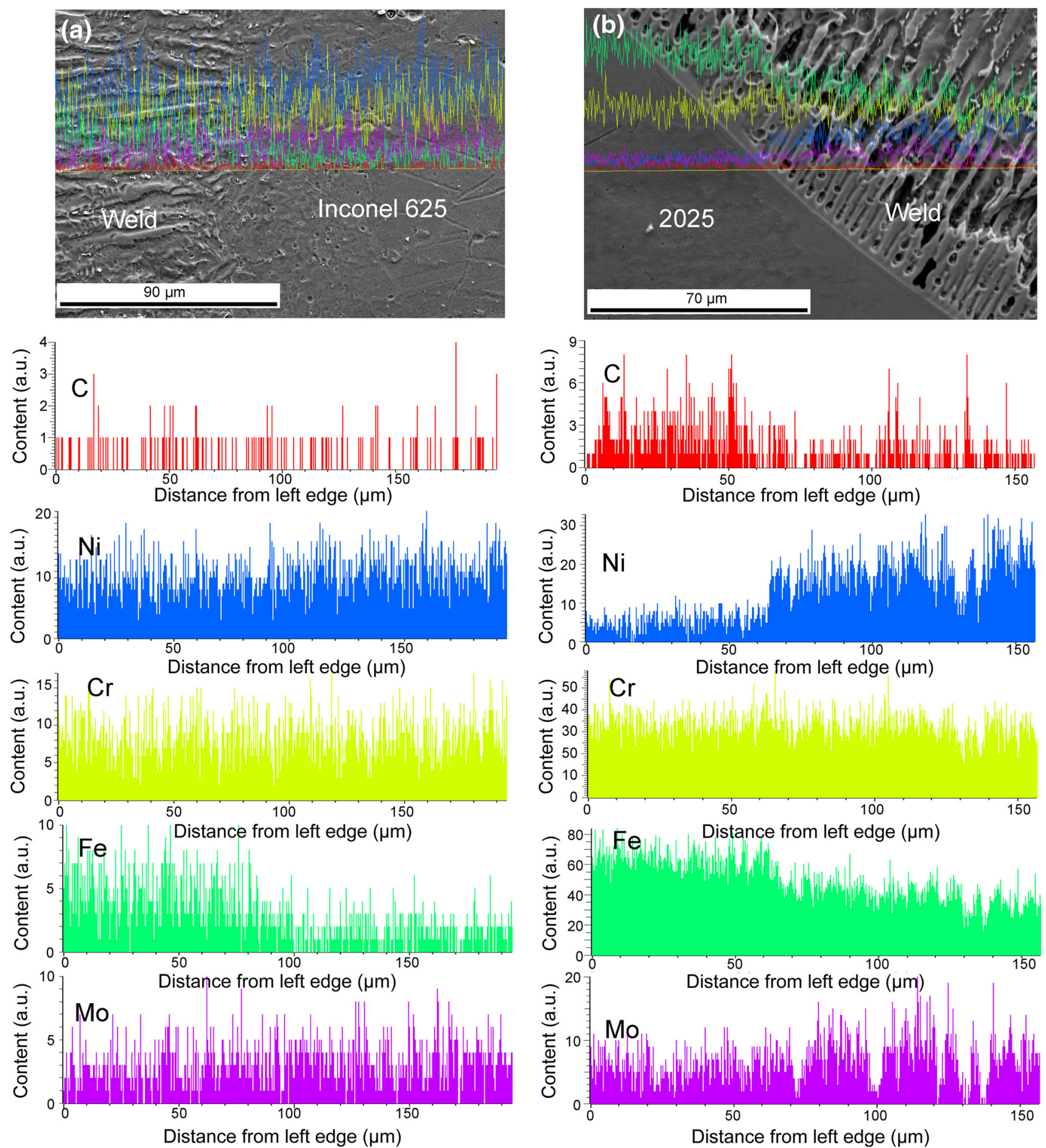

Fig. 7 Line mapping analysis on the dissimilar weldments employing ERNiCrMo-3 filler: a interface at Inconel 625 side; b interface at SAF 2205 side

Ti (0.22 wt \%), and Mo (13.91 wt $\%)$. As these elements are present in the inter-dendritic regions of the weld zone, they would be absent or found less in the matrix (Fig. 6d). This could partially deteriorate the mechanical properties of the weldment. Similar observations were reported elsewhere; the authors reported that the micro-segregation that occurs in weld fusion zones of Ni-Cr-Mo alloys leads to a situation where dendrite cores are impoverished in elements like Mo, and inter-dendritic regions are enriched in Mo, $\mathrm{Nb}$, and sometimes $\mathrm{Cr}[13,14]$. Greater amounts of $\mathrm{Nb}$ distribution occur principally in the inter-dendritic area and take the form of Nb-rich precipitates. These $\mathrm{Nb}$-rich phases 


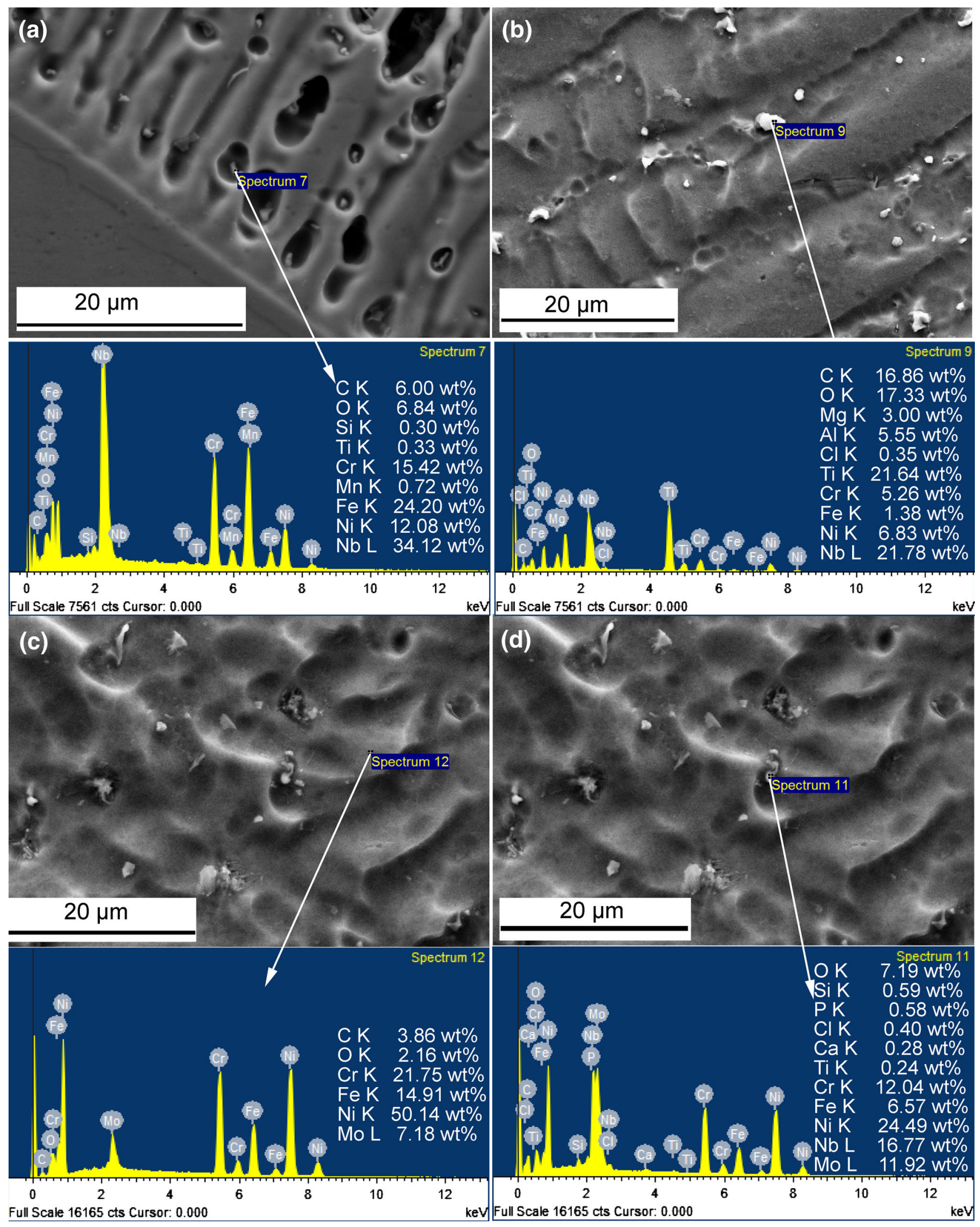

Fig. 8 SEM/EDAX point analysis on the weld zone of the dissimilar weldments of Inconel 625 and SAF 2205 employing ERNiCrMo-3 filler: a weld interface-weld zone adjacent to SAF 2205; b-d weld zone 

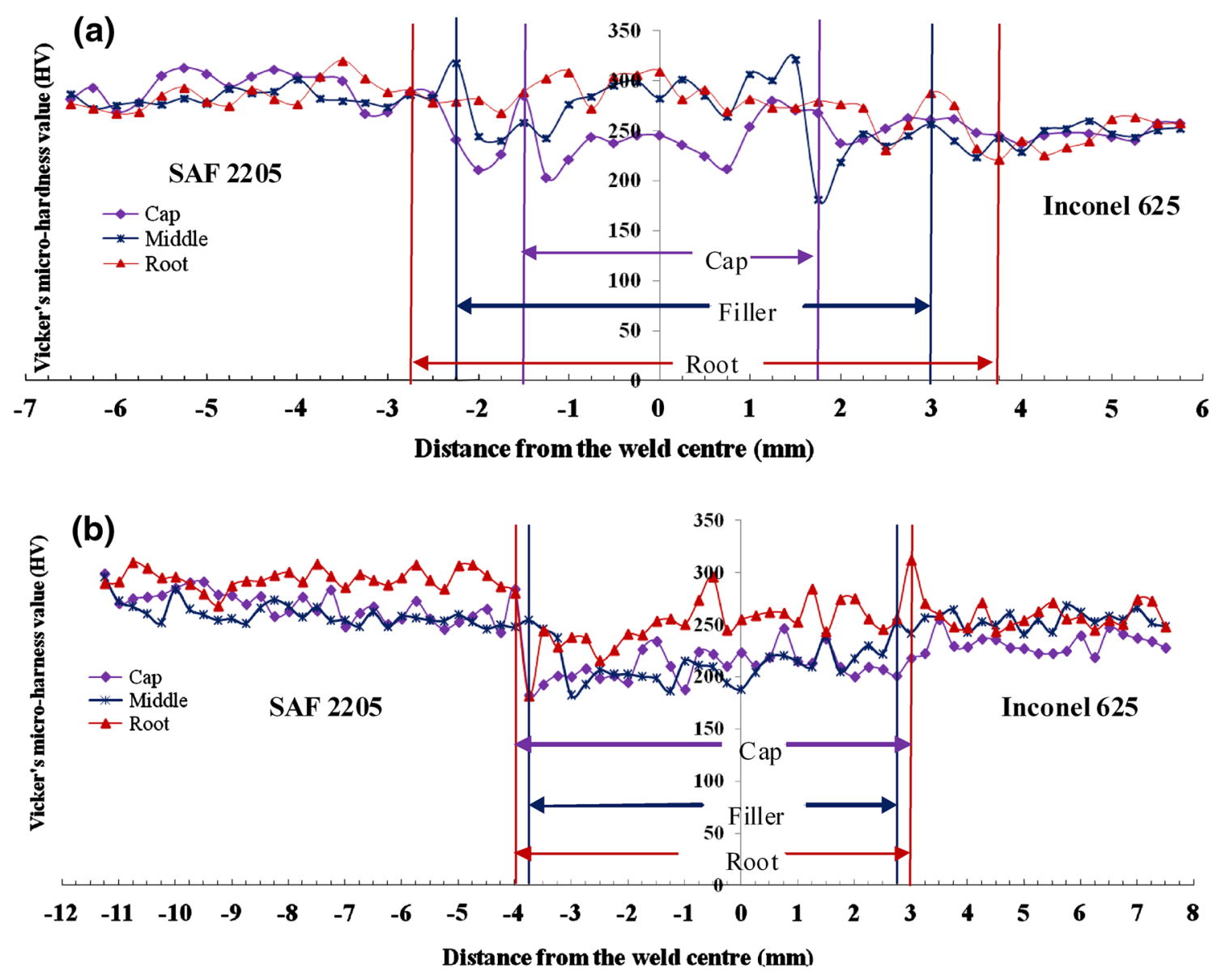

Fig. 9 Hardness profile of the dissimilar weldments of Inconel 625 and SAF 2205 employing ER2209 a, ERNiCrMo-3 b fillers

would be either $\mathrm{NbC}$ and/or Laves phase. As reported by Dupont et al. [15, 16], a higher concentration of $\mathrm{Nb}$ tends to increase the volume of $\mathrm{Nb}$-rich precipitates, while a higher $\mathrm{C}$ content leads to the formation of $\mathrm{NbC}$. However, the Laves phase forms readily with a high $\mathrm{Nb}$ and a low $\mathrm{C}$ composition, particularly when $\mathrm{Si}$ and $\mathrm{Fe}$ are also present.

\subsubsection{SEM/EDAX Analysis on ERNiCrMo-3 Weldments}

SEM and EDAX line mapping results of GTA-ERNiCrMo3 weld interface of Inconel 625 and SAF 2205 are represented in Fig. 7a and b. The results showed the enrichment of $\mathrm{Cr}$, Mo, and $\mathrm{Ni}$ in the weld zone with the meager depletion of Fe. This could be reasoned to the migration of elements during welding. However, there is a negligible elemental movement experienced from the weld zone to Inconel 625 side or vice versa. SEM/EDAX analysis at the weld zone envisaged the presence of macro-voids and the presence of secondary phases in the voids. The SEM image of ERNiCrMo-3 weld and Inconel 625 shows the fully austenitic matrix containing several types of precipitates. These precipitates were found in the dendrite and along the grain boundaries. Inconel 625 contains $0.235 \mathrm{wt} \% \mathrm{Ti}$,
$2.98 \mathrm{wt} \% \mathrm{Nb}$, and $0.022 \mathrm{wt} \% \mathrm{C}$ and hence tends to form the $\mathrm{TiC}$ and $\mathrm{NbC}$ during high-temperatures exposure. These results confirmed by EDS point analysis have been discussed in detail in the next section.

Figure 8 represents the results of SEM/EDS point analysis on ERNiCrMo-3 weld interface of both base metals. The white precipitates were observed at the weld zone shown in Fig. 8a and b, which were enriched with $\mathrm{Nb}$ and $\mathrm{Ti}$ in the Inconel 625 side. This is attributed to the formation of phases such as $\mathrm{NbC},(\mathrm{Nb}, \mathrm{Ti}) \mathrm{C}$ as reported by Hosseini et al. [9]. Some segregation of secondary phases was noticed in the SAF 2205 side (Fig. 8c, d). However, TEM and XRD analyses are required to confirm the presence of exact $\mathrm{Nb}$ rich precipitates formed in the weld zone.

\subsection{Hardness Test}

It is evident from the hardness profile that the average hardness of GTA weldments employing ER2209 was found to be higher as compared to ERNiCrMo-3 weldments, as shown in Fig. 9. The average hardness at the cap, middle, and root pass in the weld zone of ER2209 filler was found to be 243.7, 265.2, and $280.2 \mathrm{HV}$ and for the filler 
employing ERNiCrMo-3, the hardness values were observed to be 212.6, 207.3, and $253 \mathrm{HV}$, respectively. Hardness plots clearly envisaged that the hardness at the weld zone has been plummeted compared to the other zones of the weldments. The average hardness at the root pass of the ER2209 weld zone is found to be greater than ERNiCrMo-3 weld. Lower hardness envisaged at the weld interface of ER2209 weldments in different passes shall be attributed to the absence of chromium which gets depleted during welding and forms the voids as evident from the SEM/EDAX analysis. The variations in the hardness observed at the weld zone shall be attributed to the formation of different grains such as columnar, cellular, and dendritic due to solidification and multi-pass welding. The hardness at the cap of the ERNiCrMo-3 weldments can be featured due to the presence of higher amounts of $\mathrm{Nb}$ which in turn increase $\mathrm{Nb}$-rich precipitates. The hardness values at the cap and root passes show not much variation for ERNiCrMo-3 weldments. However, there exists a slightly higher difference in the hardness values across the different passes of the ER2209 weldments. This may be explained by the fact that the cooling rate after the first pass is the highest and so a finer dendrite structure results in the root compared to that in the cap [17]. Also it has been shown that the temperature difference that exists between the cap and the root results in plastic deformation within the root [18]. Lower hardness at the weld zones of these dissimilar joints could be attributed to the higher heat inputs developed during welding which resulted in slower cooling rate and hence contributed for the coarse grains in the weld zone. It is known fact that the coarse grains normally result in lower hardness.

\subsection{Tensile and Impact Studies}

It is inferred from the tensile studies on these dissimilar joints that the fracture occurred at the weld zone for both the filler metals in all the trials. Tensile test trials showed that there were no much variations in the tensile strength of the weldments for both the fillers. The fractured tensile samples are shown in Fig. 10. The average tensile strength of $718.3 \mathrm{MPa}$ for ERNiCrMo-3 and $725.7 \mathrm{MPa}$ for ER2209 weldments has been observed. Tensile properties of these dissimilar weldments are shown in Table 3. Tensile fractures were appeared to be brittle as there were no evidence of appreciable plastic deformation and ductility. Further, the SEM fractographs in Fig. 11 have shown the presence of lesser amounts of voids with cracked boundaries for both the weldments. As evident from the hardness studies, the weld hardness is lower than that of the parent metals. It could be well noticed that there is a proper match of hardness results with weld strength of these bimetallic joints. Also it is noticed that the average tensile strength of
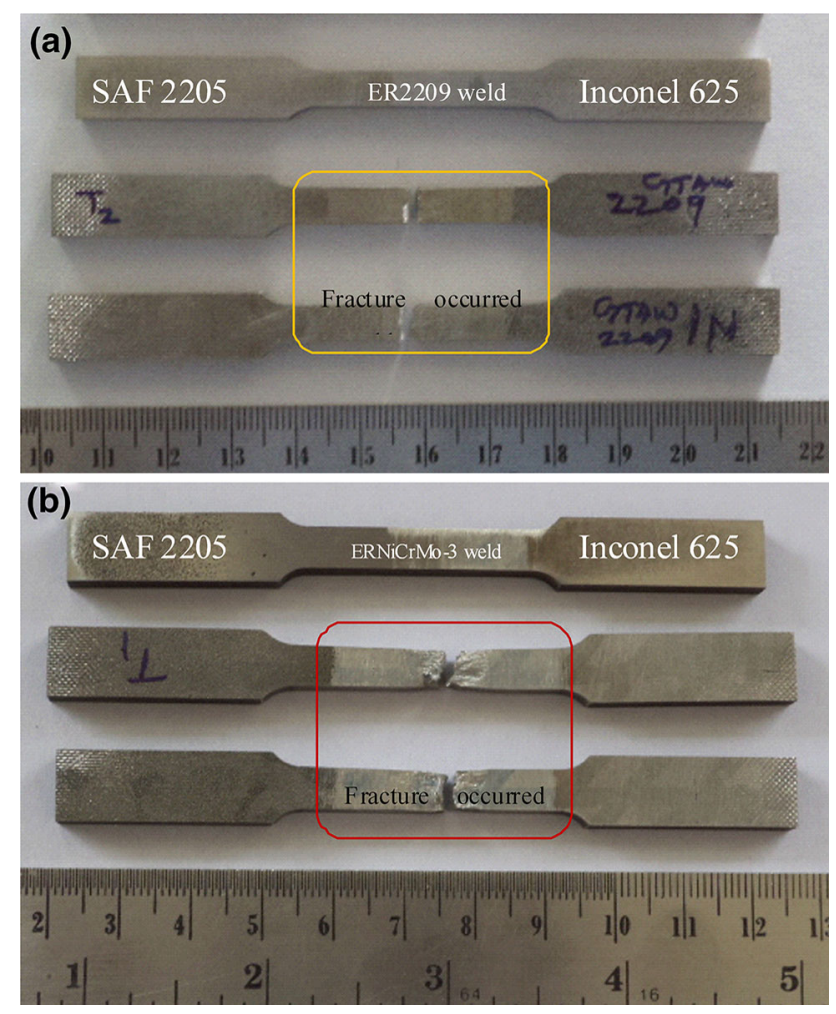

Fig. 10 Tensile samples of GTA weldments of Inconel 625 and SAF 2205 employing ER2209 a, ERNiCrMo-3 b fillers

ER2209 weldments is found to be greater than the ERNiCrMo-3 weldments. This is also supporting the results obtained from the hardness studies that the average hardness at the weld zone employing ER2209 is found to be higher than the ERNiCrMo-3 weld zone. The reason could be the formation of richer amount of carbides and the presence of nitrogen in the filler and parent metal of SAF 2205. SEM fractographs at the cap zone of the ER2209 weldments showed the presence of less dimpled with fewer ridges which confirmed that the fracture mode was shear ductile. The cap fractograph presented in Fig. $11 \mathrm{~b}$ of ERNiCrMo-3 weldments envisaged the brittle fracture. The presence of $\mathrm{Nb}$ increases the fragility of the welds. Similar observations indicated that $\mathrm{Nb}$ addition reduces the formation of ductile tear ridges and therefore suggests that increasing $\mathrm{Nb}$ content encourages inter-dendritic fracture in the cap [19]. The specimens with high $\mathrm{Nb}$ addition did not show large deformations, although there is evidence that the ruptured mechanism was still governed by void connection; i.e., the Nb-rich precipitates between the dendrites (Fig. 11b). Similar observations were made by Lee et al. [11] where the $\mathrm{Nb}$ additions have no significant role in increasing the strength and in all the levels of $\mathrm{Nb}$ addition, the fracture occurred at the fusion zone.

Charpy V-notch studies carried out on these dissimilar coupons clearly envisaged that the impact toughness of the 
Table 3 Tensile properties of the dissimilar Inconel 625 and SAF 2205 GTA weldments with different fillers

\begin{tabular}{|c|c|c|c|c|c|c|c|}
\hline Filler & Trial & $\begin{array}{l}\text { Maximum } \\
\text { load }(k N)\end{array}$ & $\begin{array}{l}\text { UTS } \\
(\mathrm{MPa})\end{array}$ & $\begin{array}{l}\text { Average } \\
\text { UTS (MPa) }\end{array}$ & $\begin{array}{l}\text { Young's } \\
\text { modulus (GPa) }\end{array}$ & $\begin{array}{l}\text { Elongation } \\
\text { at break }(\%)\end{array}$ & $\begin{array}{l}\text { Fracture } \\
\text { zone }\end{array}$ \\
\hline \multirow[t]{3}{*}{ ER2209 } & 1 & 22.98 & 751 & \multirow[t]{3}{*}{725.7} & 58.73 & 26.94 & \multirow[t]{3}{*}{ Weld region } \\
\hline & 2 & 22.27 & 728 & & 65.16 & 32.24 & \\
\hline & 3 & 21.35 & 698 & & 57.91 & 8.8 & \\
\hline \multirow[t]{3}{*}{ ERNiCrMo-3 } & 1 & 22.20 & 726 & \multirow[t]{3}{*}{718.3} & 49.91 & 16.59 & \multirow[t]{3}{*}{ Weld region } \\
\hline & 2 & 20.03 & 663 & & 56.72 & 10.89 & \\
\hline & 3 & 23.45 & 766 & & 56.53 & 17.92 & \\
\hline
\end{tabular}
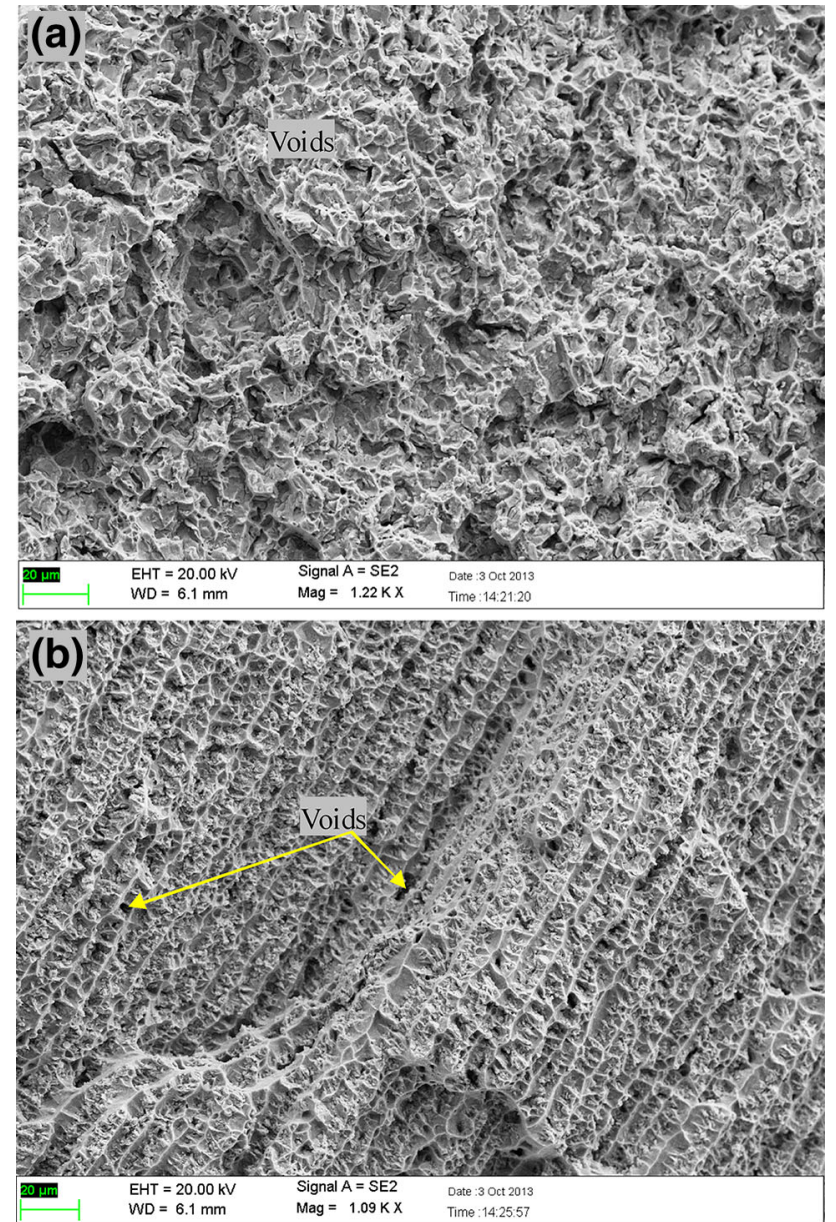

Fig. 11 SEM fractographs on the tensile coupons of GTA weldments of Inconel 625 and SAF 2205 employing ER2209 a, ERNiCrMo-3 b fillers

ERNiCrMo-3 weldments is found to be almost five times better than ER2209 weldments (Fig. 12). In both the trials, the ER2209 weldments have shown poor resistance to impact loading. The fractured surfaces are then examined using scanning electron microscopy and depicted in Fig. 13. The voids were found to be lesser and ridges appearing on the surface with cracked boundaries were witnessed for ER2209

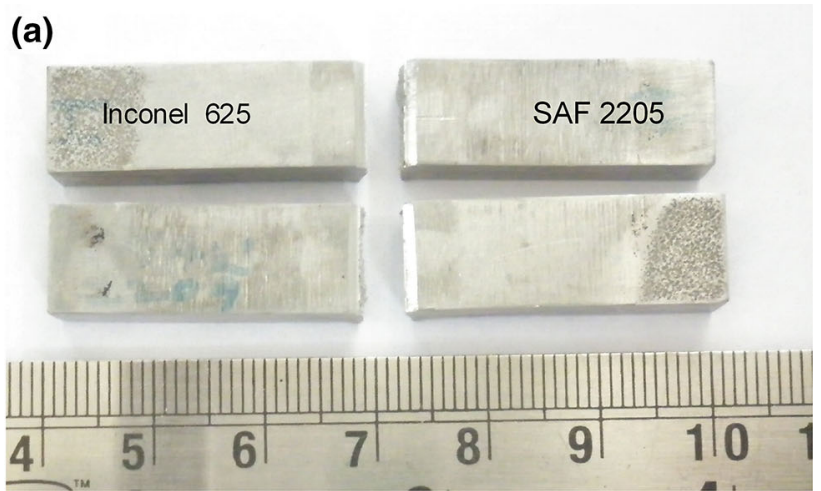

(b)

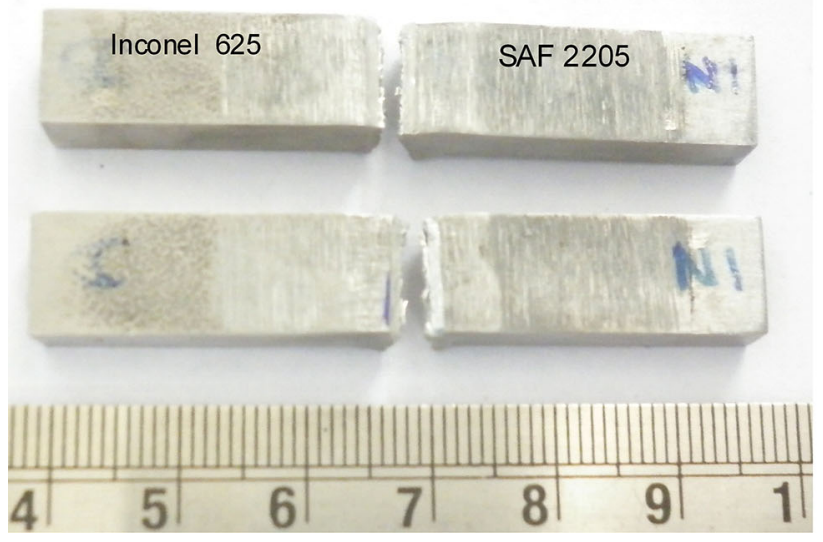

Fig. 12 Impact test samples of GTA weldments of Inconel 625 and SAF 2205 employing ER2209 a, ERNiCrMo-3 b fillers

weldments; micro-voids and dimples with the clusters of ductile tear ridges were found spread in the ERNiCrMo-3 weldments. Charpy V-notch impact studies inferred that the weldments undergo brittle fracture for ER2209 and ductilebrittle mode of fracture for ERNiCrMo-3 filler. However, the impact toughness is found to be greater for the ERNiCrMo-3 weldments (42.7 J) in comparison with the ER2209 weldments $(9.8 \mathrm{~J})$. SEM fractographs however showed the presence of dimples with the ductile tearing ridges on the fractured surface of ERNiCrMo-3 weldments. As reported by Vernot-Loier and Cortial [19], the lower toughness values 

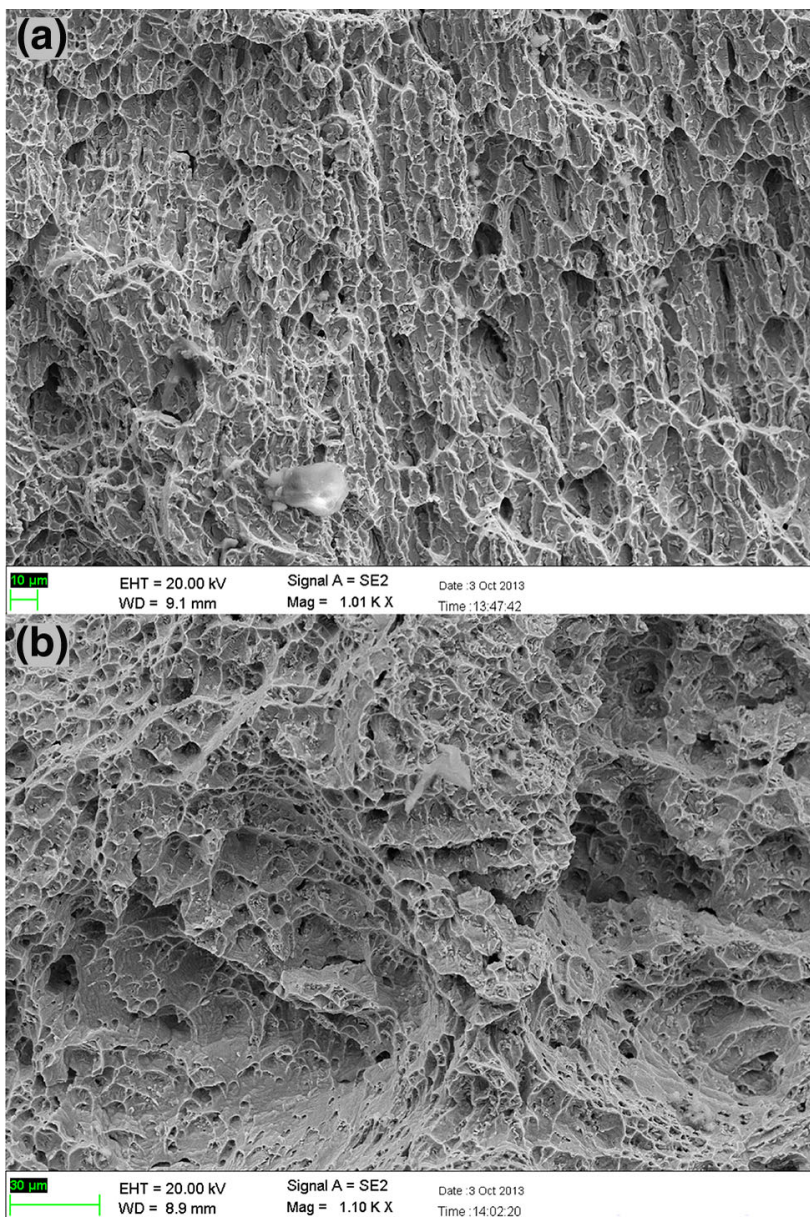

Fig. 13 SEM fractographs on the impact test samples of GTA weldments of Inconel 625 and SAF 2205 employing ER2209 a, ERNiCrMo-3 b fillers

indicated in the weldments could be attributed to the presence of $M_{6} \mathrm{C}, M_{23} \mathrm{C}_{6}$ carbides which were also witnessed from the EDS results.

\section{Conclusions}

(1) Sound joints of Inconel 625 and Duplex stainless steel could be made possible on employing GTA welding employing these filler wires.

(2) Microstructure observations showed the grain coarsening at the HAZ of SAF 2205 and segregation effects at the HAZ of Inconel 625 and these microstructural changes are attributed to the higher heat inputs developed during welding.

(3) The formation of the precipitation zone adjacent to the weld zone occurred due to the temperature differences between the base and filler metals.

(4) Line mapping analysis showed that the elements such as $\mathrm{Nb}, \mathrm{Mo}, \mathrm{Cr}$ have been enriched and appeared as precipitates in the form of segregation at the HAZ of Inconel 625 .

(5) Tensile results showed that the fracture occurred at the weld zone in both the cases of the weldments. The average ultimate tensile strength of the ER2209 weldments was found to be greater compared to ERNiCrMo-3 weldments.

(6) Weld hardness was found to be plummeted compared to other zones of the weldments.

(7) The presence of Nb-rich phases at the inter-dendritic regions rather than the core deteriorates the mechanical properties of these weldments.

(8) Impact toughness of the ERNiCrMo-3 weldments is greater than that of the ER2209 one, and the mode of fracture of the both weldments is ductile-brittle in nature.

\section{References}

[1] X.Q. Wu, H.M. Jing, Z.M. Zheng, Z.M. Yao, W. Ke, Z.Q. Hu, Mater. Sci. Eng. A 293, 252 (2000)

[2] F. Wang, D. Northwood, Mater. Charact. 31, 3 (1993)

[3] M. Blair, T.L. Stevens, Steel Casting Handbook (Steel Founders Society of America and ASM International, Materials Park, 2000), pp. $1-13$

[4] M.J. Donachie, S.J. Donachie, Superalloys: a Technical Guide (ASM International, Materials Park, 2002), pp. 10-30

[5] J.R. Daris, ASM Handbooks (ASM International, Materials Park, 1999), pp. 18-23

[6] J.C. Lippold, Weld. J. 62, 91 (1983)

[7] M. van Wijngaarden, J. Chater, Stainless Steel World, 42 (2006)

[8] H. Naffakh, M. Shamanian, F. Ashrafizadeh, J. Mater. Process. Technol. 209, 3628 (2009)

[9] H. Shah Hosseini, M. Shamanian, A. Kermanpur, Mater. Charact. 62, 425 (2011)

[10] R. Dehmolaei, M. Shamanian, A. Kermanpur, Mater. Charact. 59, 1447 (2008)

[11] H.T. Lee, S.L. Jeng, C.H. Yen, T.Y. Kuo, J. Nucl. Mater. 335, 59 (2004)

[12] D.J. Lee, Y.S. Kim, Y.T. Shin, E.C. Jeon, S.H. Lee, H.J. Lee, S.K. Lee, J.H. Lee, H.W. Lee, Metall. Mater. Int. 16, 813 (2010)

[13] G. Belloni, G. Caironi, A. Gariboldi, A. Lo Conte, P. di Milano, Trans. SMiRT 16, 1546 (2001)

[14] J.R. Crum, L.E. Shoemaker, S.D. Kiser, Special alloys and overmatching welding products solve FGD corrosion problems. Special Metals Welding Products, Technical Paper

[15] J. Dupont, J. Lippold, S. Kiser, Welding Metallurgy and Weldability of Nickel-Base alloys (Wiley, New York, 2009)

[16] J.N. DuPont, C.V. Robino, A.R. Marder, M.R. Notis, J.R. Michael, Metall. Mater. Trans. A 29, 2785 (1998)

[17] J.N. DuPont, C.V. Robino, A.R. Marder, Metall. Mater. Trans. A 29, 2797 (1998)

[18] I. Gowrisankar, A.K. Bhaduri, V. Seetharaman, D.D.N. Verma, D.R.G. Achar, Weld. J. 66, 147s (1987)

[19] C. Vernot-Loier, F. Cortial, Superalloy 718/625 (TMS, Warrendale, 1991), p. 409 